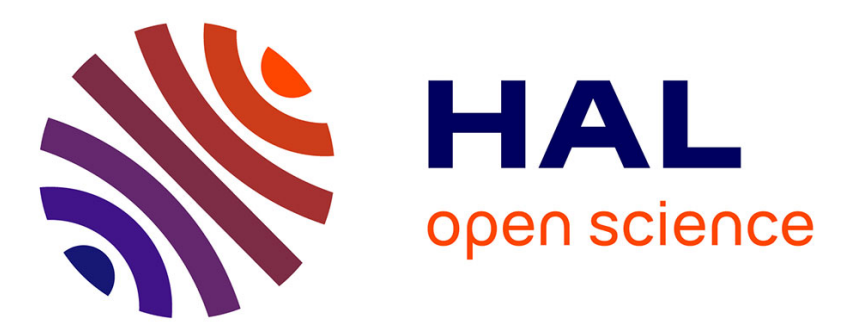

\title{
Lipase esterification in the Centrifugal Partition Reactor: Modelling and determination of the specific interfacial area
}

Claudia Nioi, Philippe Destrac, Jean-Stéphane Condoret

\section{To cite this version:}

Claudia Nioi, Philippe Destrac, Jean-Stéphane Condoret. Lipase esterification in the Centrifugal Partition Reactor: Modelling and determination of the specific interfacial area. Biochemical Engineering Journal, 2019, 143, pp.179-184. 10.1016/j.bej.2019.01.006 . hal-02283687

\section{HAL Id: hal-02283687 \\ https://hal.science/hal-02283687}

Submitted on 11 Sep 2019

HAL is a multi-disciplinary open access archive for the deposit and dissemination of scientific research documents, whether they are published or not. The documents may come from teaching and research institutions in France or abroad, or from public or private research centers.
L'archive ouverte pluridisciplinaire HAL, est destinée au dépôt et à la diffusion de documents scientifiques de niveau recherche, publiés ou non, émanant des établissements d'enseignement et de recherche français ou étrangers, des laboratoires publics ou privés. 


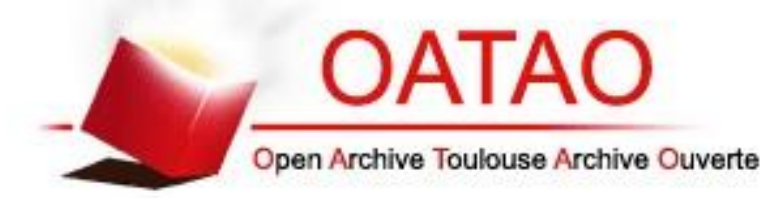

Open Archive Toulouse Archive Ouverte

OATAO is an open access repository that collects the work of Toulouse researchers and makes it freely available over the web where possible

This is an author's version published in: http://oatao.univ-toulouse.fr/24257

Official URL: https://doi.org/10.1016/.j.bej.2019.01.006

\section{To cite this version:}

Nioi, Claudia Lipase esterification in the Centrifugal Partition Reactor: Modelling and determination of the specific interfacial area. (2019) Biochemical Engineering Journal, 143. 179-184. ISSN 1369-703X

Any correspondence concerning this service should be sent to the repository administrator: tech-oatao@listes-diff.inp-toulouse.fr 


\title{
Lipase esterification in the Centrifugal Partition Reactor: Modelling and determination of the specific interfacial area
}

\author{
Claudia Nioi ${ }^{*}$, Philippe Destrac, Jean-Stéphane Condoret* \\ Université de Toulouse, Laboratoire de Génie Chimique, UMR INPT, UPS, CNRS 5503, 4 Allée Emile Monso, F-31030, Toulouse, France
}

H I G H L I G H T S

- Centrifugal Partition Reactor for two phase enzyme reactions.

- Determination of kinetics for enzyme esterification of oleic acid with $n$-butanol.

- Modelling of CPR based on hypothesis of plug flow and no mass transfer limitation.

- Modelling was used to estimate the specific interfacial area of CPR.

- Specific interfacial area of the CPR is independent of the mobile phase flow rate.

Keywords:

Enzymatic reactor

Centrifugal reactor

Specific interfacial area

\section{A B S T R A C T}

Recently the Centrifugal Partition Chromatography (CPC) device, called Centrifugal Partition Reactor (CPR), was proposed to operate biocatalytic reactions in two phase systems in continuous mode. However, information about hydrodynamic behavior in this device for operation of enzymatic reactions is still missing. In this study, in order to propose a modelling of this type of reactor, we firstly determined in a batch reactor the kinetics constants of a model reaction, the esterification of oleic acid with $n$-butanol, catalyzed by Rhizomucor miehei lipase. This reaction was described by a Ping Pong bi-bi mechanism with alcohol inhibition and specific experiments were done to determine the kinetic constants. Specific interfacial area in the batch reactor has to be known and its determination was done by measuring droplets size of organic phase by using a microscope. Experimental conversion values of oleic acid obtained in the continuous operation of the CPR, enabled the modelling to give an estimation of the value of the specific interfacial area in the CPR, which was found around $15,000 \mathrm{~m}^{2} . \mathrm{m}^{-3}$. The value of the specific interfacial area was shown here to be independent of the mobile phase flow rate, an important feature to characterize such an intensified enzymatic reactor.

\section{Introduction}

Process intensification is a promising development for the chemical process industry, aiming at better production efficiency, yielding lower costs, enhanced safety and reduced environmental pollution [1]. In this context intensified technologies for continuous reactors are researched and developed. Our previous works [2] have demonstrated the potential of a new type of intensified reactor, the Centrifugal Partition Reactor (CPR), to operate a continuous two phase enzymatic esterification. The CPR is based on the use of a conventional Centrifugal Partition Chromatographic apparatus (CPC) [3]. The system consists in a series of twins cells engraved on a disk and connected in cascade by ducts (Fig.1). Disks are stacked to form a column called "rotor". This latter is rotated and is submitted to a constant centrifugal field [3]. In this case the stationary phase is the aqueous phase which contains the enzyme while the organic phase contains hydrophobic substrate. In our previous work [2], esterification of oleic acid by butanol was tested as a model reaction, using lipase from Rhizomucor miehei as the catalyst. Oleic acid conversion of up $85 \%$ was obtained and maintained during $30 \mathrm{~h}$ of continuous operation. These results were better than those obtained for continuous lipase esterification using different process intensification technologies [2]. The productivity of CPR was shown to be two fold higher $\left(40.5 \mathrm{~g} \cdot \mathrm{L}^{-1} \cdot \mathrm{h}^{-1}\right)$ than the one of the batch reactor $\left(21.6 \mathrm{~g} . \mathrm{L}^{-1} \cdot \mathrm{h}^{-1}\right)$ [2]. In this previous work influence of parameters was studied and allowed demonstrating that the CPR device compares with a conventional agitated batch reactor for operation of an enzymatic reaction in a two phase system [2,4]. Influence of CPR operating conditions upon conversion of oleic acid was also assessed. Especially,

\footnotetext{
* Corresponding authors.

E-mail addresses: claudia.nioi@u-bordeaux.fr (C. Nioi), jeanstephane.condoret@ensiacet.fr (J.-S. Condoret).
} 


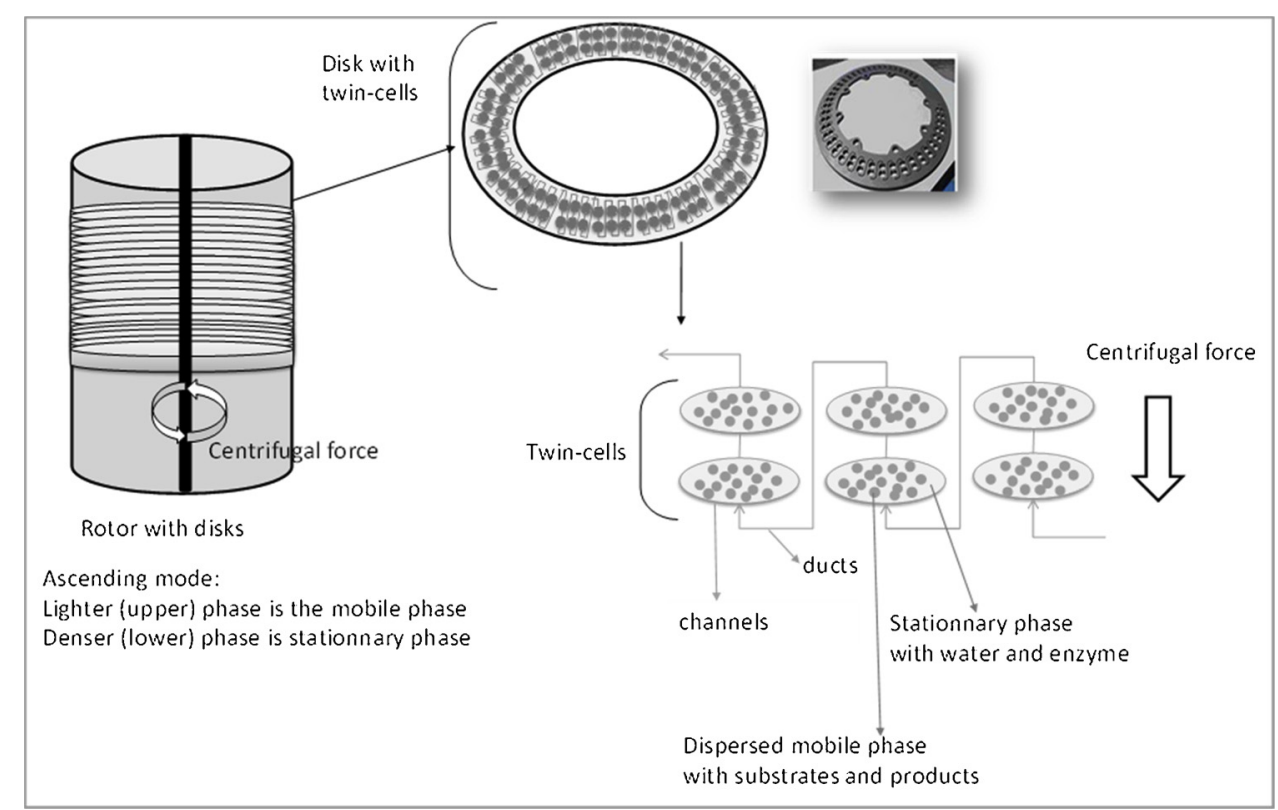

Fig. 1. Diagram of CPR reactor. The rotor consists in 21 disks. Each disk is composed of 90 twin-cells linked by ducts.

an unexpected negative influence of the rotation speed was pointed out. This result was indeed related to our specific operational procedure where the CPR is hydrodynamically equilibrated at the highest flowrate and lower rotation speed [2]. In this case, increasing rotation speed is likely to lead to a decrease of interfacial area, which causes lower performance, as the global kinetics are directly related to the interfacial area. Note that, similarly, diminution of conversion at higher rotation speed was also observed for other types of centrifugal reactors $[5,6]$. Nevertheless, further studies are necessary to better understand hydrodynamics of the CPR device and especially interfacial area, an important parameter for interface catalyzed enzymatic reactions.

Also, conversion was reported to decrease when mobile phase flow rate is increased because of the decrease of the residence time [2,4]. In our previous works [7] upon so-called "dynamic mixing intensified reactors" (Corning reactor, Chart reactor...) opposite results were observed. Detailed description of dynamic mixing reactors can be found in [7]. Indeed, in the case of dynamic mixing intensified reactors, at high flow rate, the negative effect of the residence time reduction is compensated by higher mass transfer and interfacial area. This globally results in a weak influence of the mobile phase flow rate on conversion performance. In the CPR device this levelling off effect was not observed [2], indicating that mass transfer and interfacial area are probably independent from the mobile phase flow rate. In order to better understand the influence of this parameter on conversion performance and to "optimize" the choice of reaction operating conditions, the present study proposes to evaluate the values of the specific interfacial area in the CPR and to assess the influence of mobile phase flow rate. This can be done from modelling of the reactor, with the knowledge of the enzymatic kinetics. Applying this modelling to a set of experimental conversion data enables indeed to determine the interfacial area. After this value is known, modelling can also be a useful tool to predict the influence of other parameters, such as substrate or enzyme concentration, and allows optimization of the reactor operation.

\section{Experimental part}

\subsection{Materials}

As mentioned in previous work [2] the R. miehei lipase was from Sigma Aldrich (Saint Quentin Fallavier, France). Lipase activity (918 $\mathrm{AU} \mathrm{mL}^{-1}$ ) was spectrophotometrically determined by following the hydrolysis of p-nitrophenyl butyrate (pNPB) at $405 \mathrm{~nm}$ [2]. Oleic acid (purity 95\%), heptane, $n$-butanol, were obtained from Fisher Scientific (Illkirch, France).

\subsection{Batch reactor and $C P R$ experiments}

To identify kinetic parameters of the esterification reaction model used here, reactions were conducted using an agitated glass reactor $(200 \mathrm{~mL})$, equipped with a four-blade turbine impeller. The operating method of batch reactions was previously described [2]. In order to evaluate the impact of various parameters (substrates and enzyme concentrations) on initial reaction rate the operating conditions were: aqueous/heptane $(70 / 30 \mathrm{v} / \mathrm{v})$ two phase mixture, $n$-Butanol: 0.01 0.4 mol. $\mathrm{L}^{-1}$, oleic acid $0.032-0.18$ mol.L ${ }^{-1}$, lipase: $0.1-10$ g.L $\mathrm{L}^{-1}$ in phosphate buffer $0.1 \mathrm{M}$, rotational speed: $800-1600 \mathrm{rpm}$. All batch experiments were carried out in triplicate.

For CPR experiments, data correspond to experiments reported in our previous work [2]. They were performed in a CPC-250-F apparatus, manufactured by Armen Instrument (Saint-Avé, France). The column consists of 21 disks stacked to form a column called rotor (Fig. 1). The disks are composed of 90 twin cells of $100 \mu \mathrm{L}$ for each cell linked by ducts. The total volume (cells and ducts) is $200 \mathrm{~mL}$. The liquid system used for batch and reactor experiments is composed of an organic phase of heptane with $n$-butanol and an aqueous phase at $\mathrm{pH}$ 5.6. The two phases were equilibrated (shaken three times a few seconds in a glass flask at $22^{\circ} \mathrm{C}$ and less to the settle for $2 \mathrm{~h}$ ) before use for experiments.

\subsection{Modelling of the CPR steady state operation}

The CPR can be considered as a plug flow reactor where interfacial area can be enhanced compared to the batch reactors. Indeed, due to the very high number of mixing cells (our CPR device is composed of 90 twin-cells, thus a total of 180 cells), very weak axial dispersion can be assumed in the mobile phase flow. Also, mass transfer towards interface is assumed to be non limiting.

This hypothesis is based on the comparison of characteristic times, as done by Kraai [4]. The characteristic time for reaction is in the range of a few tenths of minutes. Indeed, this characteristic time was evaluated as the one corresponding to about $65 \%$ conversion in the CPR obtained for a flow rate of $3.5 \mathrm{~mL} . \mathrm{mn}^{-1}$ [2]. This flow rate value corresponds to a residence time of about $25 \mathrm{~min}$. The mass transfer 
characteristic time was obtained from the value of the volumetric mass transfer coefficient $\left(\mathrm{k}_{\mathrm{o}} \mathrm{a}\right)$. From the study of Marchal et al. a value of $\left(\mathrm{k}_{\mathrm{o}} \mathrm{a}\right)$ in the range of $0.02-0.4 \mathrm{~s}^{-1}$ was estimated [8]. So, mass transfer characteristic time is low (2.5-50 s) compared to the reaction characteristic time and this validates our hypothesis.

The reactor was modelled using the conventional equation for an ideal plug flow reactor (eq. 1):

$V_{C P R}=F C_{0} \int_{0}^{x} \frac{d X}{v_{C P R} \times a_{C P R}}$

where $V_{C P R}$ is the total volume of the CPR reactor $\left(\mathrm{m}^{3}\right), F$ is the volume mobile phase flow rate $\left(\mathrm{m}^{3} \cdot \mathrm{s}^{-1}\right), C_{o}$ is the initial concentration of oleic acid (mol. $\mathrm{m}^{-3}$ ) in the mobile phase, $X$ the reaction conversion rate in the CPR device. $a_{C P R}$ is the specific interfacial area in the CPR referred to the total volume of the CPR. The specific interfacial area $a_{C P R}$ must be introduced here because the kinetic of this type of enzymatic reactions is directly proportional to the interfacial area. So, the reaction rate $v_{\mathrm{CPR}}$ has to be expressed per unit of interfacial area, in mol. $\mathrm{m}^{-2} \mathrm{~s}^{-1}$. $v_{\mathrm{CPR}}$ is determined by using equation of the Ping-Pong kinetic model with competitive inhibition by only one of the substrates (here the alcohol, at the conditions investigated in this study) $[9,12]$.

As mentioned, because this kind of enzymatic reaction takes place at the interface, it is usually assumed that the global kinetics are the product of the intrinsic enzyme kinetics and the specific interfacial area $[4,13,14]$. Here, in the kinetic equation, we have used the values of parameters which were obtained from initial velocity experiments in a batch reactor with a given specific interfacial area $a_{\text {batch }}$ determined in Section 3. As already mentioned, the reaction rate $v_{\mathrm{CPR}}$ has to be expressed per $\mathrm{m}^{2}$ of interface in the equation of the CPR (Eq. (1)), thus it is obtained by the following equation (Eq. (2)) where the kinetic equation, referred to the volume of organic phase, is divided by $a_{\mathrm{batch}}$. So, in Eq. (2), $v_{\mathrm{CPR}}$ is expressed in mole $\mathrm{s}^{-1} \mathrm{~m}^{-2}$ :

$v_{C P R}=\frac{\left(k_{e n z} \times C_{e n z}\right) \times([O A][B U])-\left[H_{2} O\right][B O] / K_{e q}}{K_{O A} \times[B U] \times\left[1+\frac{[B U]}{K i_{B U}}\right]+K_{B U} \times[O A]+[O A][B U]} \times \frac{1}{a_{\text {batch }}}$

$a_{\text {batch }}\left(\mathrm{m}^{2} \cdot \mathrm{m}^{-3}\right)$ is the specific interfacial area in the batch reactor referred to the volume of the organic phase, $k_{e n z}$ is the enzymatic constant $\left(\mathrm{mol} \mathrm{g}^{-1} \cdot \mathrm{min}^{-1}\right)$ referred to the volume of aqueous phase, $K_{O A}$ and $K_{B U}$ are the Michaelis Menten constants for oleic acid and $n$-butanol respectively referred to the volume of the organic phase $\left(\mathrm{mol} \mathrm{m}^{-3}\right)$, $K i_{B U}$ is the inhibition constant for $n$-butanol, referred to the volume of the organic phase $\left(\mathrm{mol} \mathrm{m}^{-3}\right)$. In this equation, occurrence of a chemical equilibrium is accounted for by adding a term in the numerator in accordance with the Haldane equation $[17,18]$. The value of the equilibrium constant of the reaction expressed in concentration, $\mathrm{K}_{\mathrm{eq}}$, was estimated as $\mathrm{K}_{\mathrm{eq}}=78$ from experimental conversion values at equilibrium given in our previous works [15]. $C_{e n z}$ is the lipase concentration in the aqueous phase (g. $\left.\mathrm{L}^{-1}\right),[\mathrm{OA}],[\mathrm{BU}],[\mathrm{BO}]$ and $\left[\mathrm{H}_{2} \mathrm{O}\right]$ are the concentrations $\left(\mathrm{g}_{\text {enz }} \cdot \mathrm{L}^{-1}\right.$ ) of oleic acid, $n$-butanol, butyl ester and water in the organic phase, respectively. Indeed, previous studies have indicated that the enzymatic reaction takes place at the interface of the organic and aqueous phase where the active site of the lipase is oriented towards the organic phase $[4,13,16]$. Thus, only substrates dissolved in the organic phase can be converted.

To calculate reactant and product concentrations in the organic phase, a mass balance equation at phase equilibrium was used. The oleic acid (OA) concentration (mol. $\mathrm{m}^{-3}$ ) is thus given by Eq. (3):

$[O A]=\frac{n_{O A}}{V_{\text {org }}}(1-X)$

This assumes that oleic does not partition because its solubility in the aqueous phase is negligible. $n_{0 \mathrm{~A}}$ is the initial intake of oleic acid (mol), $V_{\text {org }}$ is the organic phase volume $\left(\mathrm{m}^{3}\right)$ and $\mathrm{X}$ the conversion.

Because $n$-butanol (BU) partitions between the two phases, its concentration is defined by Eq. (4):

$[B U]=\frac{n_{B U}-n_{O A} X}{V_{\text {org }}+\frac{V_{a q}}{m}}$

where $\mathrm{n}_{\mathrm{BU}}$ and $\mathrm{n}_{\mathrm{OA}}$ are the initial number of moles of $n$-butanol and oleic acid, respectively (mol), $V_{\text {org }}$ is the volume of organic phase $\mathrm{m}^{3}$ ), $\mathrm{V}_{a q}$ the volume of the aqueous phase $\left(\mathrm{m}^{3}\right)$ and $m$ is the partition coefficient of $n$-butanol expressed as the ratio of the butanol concentration in heptane by its concentration in the aqueous phase. Value of the partition coefficient was taken as $\mathrm{m}=3.7$ from our previous works [15].

For butyloleate $[\mathrm{BO}]$ the concentration can be calculated from oleic acid conversion by Eq. (5) as follows:

$[B O]=\left(\frac{n_{O A}}{V_{\text {org }}}\right) X$

This assumes again that the ester does not partition because it is indeed more hydrophobic than oleic acid.

The concentration of water in the organic phase $\left[\mathrm{H}_{2} \mathrm{O}\right]$ was assumed to be constant and equal to its saturation value in the organic phase (considered as a constant whatever the concentration of the other compounds). Indeed, the large amount of water of the aqueous phase maintains the saturation of the organic phase. This saturation value was taken as $5 \mathrm{~mol} \cdot \mathrm{m}^{-3}[19]$.

\subsection{Kinetic modelling in batch reactor}

The experimental initial reaction rate of esterification in the batch reactor was obtained by linear regression of experimental data over the first $10 \mathrm{~min}$ (concentration of products as a function of time). The values of kinetic parameters were determined by sum squared errors minimization between experimental and calculated data from the kinetic model. Concentrations in the organic phase were computed as described in the preceding paragraph (Eqs. (3)-(5)). This procedure was carried out using the solver tool of the Microsoft Excel 2007 spreadsheet.

\subsection{Determination of interfacial area in batch reactor}

For a typical reaction condition constituted of $0.032 \mathrm{~mol} . \mathrm{L}^{-1}$ of oleic acid and 0.096 mol. $\mathrm{L}^{-1}$ of $n$-butanol in $30 \mathrm{~mL}$ of heptane and 1 g. $\mathrm{L}^{-1}$ of enzyme in $100 \mathrm{~mL}$ of aqueous phase, the two phases were mixed for $15 \mathrm{~min}$ in the batch reactor at 800 impeller rotation speed. After mixing, a sample of organic phase was withdrawn and placed on a slide for observation with a microscope. Manual counting of droplets of each diameter class was done from photographs. This made possible to compute the Sauter mean drop size diameter $\left(d_{s}\right)$ using the Eq. (6):

$d_{s}=\frac{\Sigma N_{i} d_{i}^{2}}{\sum_{i}\left(\frac{N_{i}}{6}\right) \times d_{i}^{3}}$

where $\mathrm{N} i$ represents the number of droplets and di is the diameter (m) of droplets.

\section{Results and discussion}

\subsection{Determination of the kinetic parameters of esterification of oleic acid with $n$-butanol by $R$. miehei lipase}

Kinetics of this reaction have been already studied by Kraai et al. [4] but a different value of the partition coefficient $m$ had been taken $\left(\mathrm{m}=1.83\right.$, experimentally determined at $30^{\circ} \mathrm{C}$ ). Because this value influences the value of the kinetic constants, a particular study was devoted here to the evaluation of the intrinsic kinetic parameters of the model reaction. For this purpose, enzymatic reaction experiments were 


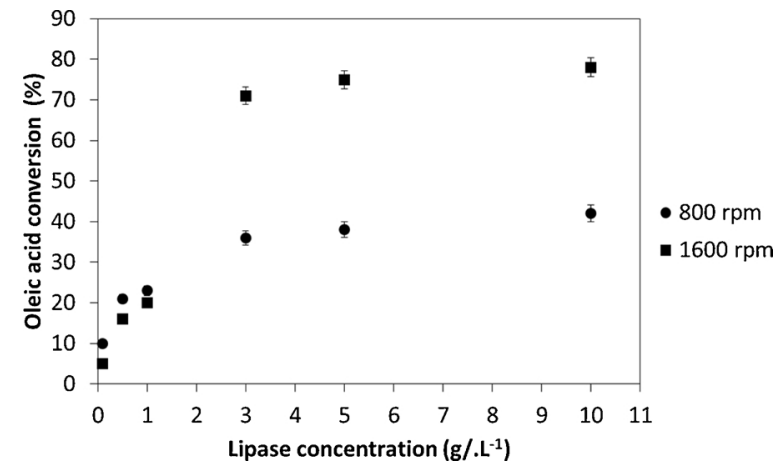

Fig. 2. Oleic acid conversion versus concentration of enzyme $\left(0.1 \mathrm{~g} \mathrm{~L}^{-1}\right.$ to 10 g. $\left.\mathrm{L}^{-1}\right)$. Operating conditions in batch reactor: $n$ - $\mathrm{BuOH}\left(0.097 \mathrm{~mol} . \mathrm{L}^{-1}\right)$ /oleic acid $\left(0.032 \mathrm{~mol} \mathrm{~L}^{-1}\right)=3(\mathrm{~mol} / \mathrm{mol})$, rotation speed $800 \mathrm{rpm}$ and $1600 \mathrm{rpm} . \mathrm{T}=22^{\circ} \mathrm{C}$.

carried out in a batch reactor at room temperature $\left(22^{\circ} \mathrm{C}\right)$ as described in Material and Methods.

First the influence of the enzyme concentration (from 0.1 g.L $\mathrm{L}^{-1}$ to $10 \mathrm{~g} . \mathrm{L}^{-1}$ ) was studied in order to determine the optimal enzyme concentration for the following study (Fig. 2). Indeed, it is well known that lipase activity varies as a function on enzyme concentration and on the ratio of free available interfacial area [9-11]. Thus, to optimize the conversion rate, value of lipase concentration that yields at interface saturation for the operating interfacial area must be determined. This has been done for two rotation speeds (Fig. 2).

At these operating conditions the conversion increases and tends to a "plateau". This behaviour was already reported in the literature for lipase-catalyzed reactions [9-11] and corresponds to saturation of the interface by the enzyme molecules.

So, to avoid operation on the saturation plateau whatever the rotation greater than $800 \mathrm{rpm}$, (Fig. 2), an enzymatic concentration of $1 \mathrm{~g} . \mathrm{L}^{-1}$ was chosen to study the influence of substrate concentrations on the kinetic study. We chose a rotation speed of $800 \mathrm{rpm}$ because it proved to be more suitable for the visual determination of interfacial area of the batch reactor (see paragraph 2.5).

To study the occurrence of substrate inhibition, the effect of the initial concentration of both $n$-butanol (from $0.03 \mathrm{~mol} . \mathrm{L}^{-1}$ to 0.4 mol. $\mathrm{L}^{-1}$ ) and oleic acid (from $0.032 \mathrm{~mol} . \mathrm{L}^{-1}$ to $0.18 \mathrm{~mol} . \mathrm{L}^{-1}$ ) on the initial reaction rate were investigated (Fig. 3A and 3B). The initial reaction rates referred to the volume of organic phase (moles of butyl oleate. $\mathrm{L}^{-1} \cdot \mathrm{min}^{-1}$ ) were obtained from the slope of the linear portions of the experimental oleic acid concentration values versus time. As shown in Fig. $3 \mathrm{~A}$ at higher $n$-butanol concentrations the initial reaction rate reaches a maximum around $0.1 \mathrm{mol.L} \mathrm{L}^{-1}$ and at higher concentrations the initial reaction rate decreases. This behaviour indicates that enzyme inhibition by alcohol takes place in accordance with the mechanism of lipases catalysed reactions [4,9]. For oleic acid, at the conditions investigated, no inhibition was evidenced (Fig. 3B).
Table 1

Identified kinetic constants.

\begin{tabular}{ll}
\hline Parameter & Value \\
\hline $\mathrm{K}_{\mathrm{enz}}\left(\mathrm{mol} \cdot \mathrm{min}^{-1} \cdot \mathrm{g}^{-1}\right)$ & $0.0042 \pm 0.0008$ \\
$\mathrm{~K}_{\mathrm{OA}}\left(\mathrm{mol} . \mathrm{L}_{\text {org }}^{-1}\right)$ & $0.0409 \pm 0.009$ \\
$\mathrm{~K}_{\mathrm{BU}}\left(\mathrm{mol} . \mathrm{L}_{\text {org }}^{-1}\right)$ & $0.0416 \pm 0.007$ \\
$\mathrm{~K}_{\mathrm{BU}}\left(\mathrm{mol}_{\mathrm{Lrg}}^{-1}\right)$ & $0.2277 \pm 0.04$ \\
\hline
\end{tabular}

Esterification of fatty acids with alcohols using lipase was modelled using the Ping Pong Bi-Bi mechanism [4,9,20,21]. Thus, using nonlinear regression, the initial reaction rates were fitted to the kinetic equation of this model given by eq. 7 :

$v_{\text {init }}=\frac{\left(k_{\text {enz }} \times C_{e n z}\right) \times([A O][B U])}{K_{O A} \times[B U] \times\left[1+\frac{[B U]}{K i_{B U}}\right]+K_{B U} \times[O A]+[O A][B U]}$

where $v_{\text {init }}$ is expressed per unit of organic phase volume (mol. L org. ${ }^{-1} \mathrm{~min}^{-1}$ ).

The identified kinetic parameters are shown in Table 1.

Note that value for $K_{e n z}$ is referred to aqueous phase volume while all other constants are referred to organic phase volume. The kinetic constants found in this study are in the same range than values reported by Kraai et al., in 2008 [4]. To predict the initial reaction rate using Eqs. (3)-(5) and (7) were used. The calculated data are presented in Fig. 3A and 3B. The average error between calculated and experimental initial reaction rate was $22 \%$.

\subsection{Determination of the specific interfacial area in the batch reactor}

As we mentioned in paragraph 2.5, Eq. (2) needs the knowledge of the specific interfacial area of the batch reactor referred to the organic phase volume, $a_{\text {batch }}$ (Eq. (8)). This value can be obtained from the knowledge of the mean diameter of the droplets.

$a_{\text {batch }}=\frac{6}{d_{s}}$

Where $d_{s}$ the Sauter mean droplet diameter (m).

From analysis of pictures and Eq. (7), the mean drop size diameter in batch reactor was estimated at $425 \mu \mathrm{m}$. Thus, at our experimental conditions, the specific interfacial area in our stirred batch reactor (at $800 \mathrm{rpm}$ ) is computed by Eq. ( 8 ) and its value was found as 14,120 $\mathrm{m}^{2} \mathrm{~m}^{-3}$, referred to the organic phase volume (Fig. 4). According to Albasi et al., droplet diameters for similar conditions for lipase reaction in tank reactor were observed in the same range [22].

\subsection{Determination of specific interfacial area in continuous operation of the Centrifugal Partition Reactor}

The conversion values for different experiments at 0.5 g.L ${ }^{-1}$ enzyme concentration are given in Table 2.
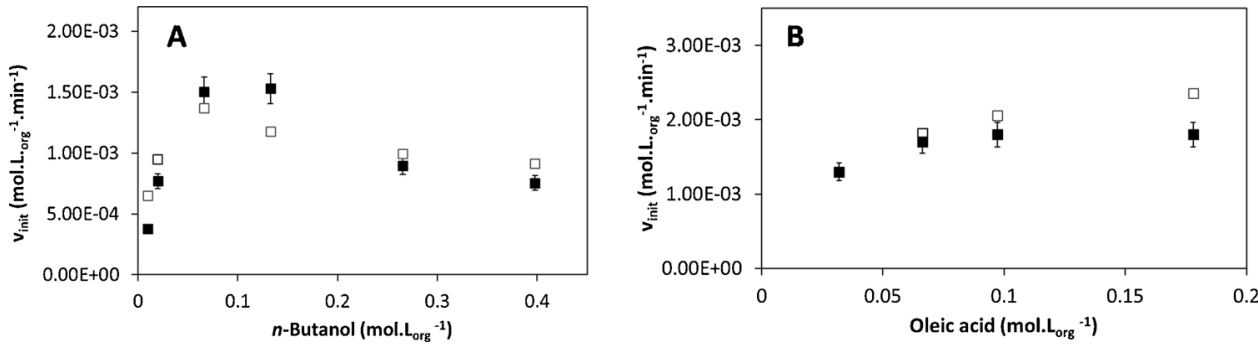

Fig. 3. A) Initial reaction rate versus $n$-butanol concentration (from $0.03 \mathrm{~mol} \mathrm{~L}^{-1}$ to $0.4 \mathrm{~mol} \mathrm{~L}^{-1}$ ). Operating conditions: $0.032 \mathrm{~mol} \mathrm{~L}^{-1}$ of oleic acid, $1 \mathrm{~g} \mathrm{~L}^{-1}$ of lipase, rotation speed $800 \mathrm{rpm}, \mathrm{T}=22^{\circ} \mathrm{C}$. B) Initial reaction rate versus oleic acid concentration (from $0.032 \mathrm{~mol} \mathrm{~L}^{-1}$ to $0.18 \mathrm{~mol} \mathrm{~L}^{-1}$ ). Reaction conditions: $n$-butanol to oleic acid ratio $=3(\mathrm{~mol} / \mathrm{mol}), 1 \mathrm{gL}^{-1}$ of lipase concentration, $800 \mathrm{rpm}$ agitation. $\mathrm{T}=22^{\circ} \mathrm{C}$. Experimental data are represented by black squares and calculated data based on the kinetic model (Eq (7)) by white squares. The average error between calculated and experimental data was $22 \%$. 


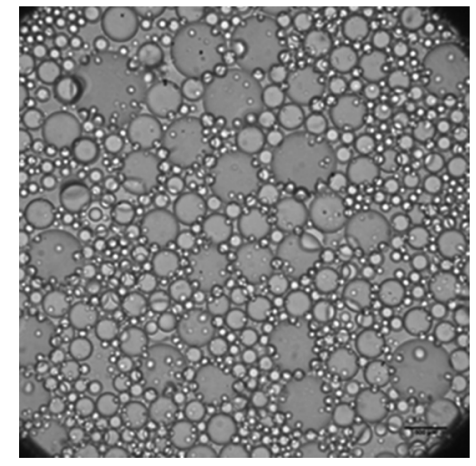

Fig. 4. Microscope image of droplets from the batch reactor. Operating conditions: $0.032 \mathrm{~mol} . \mathrm{L}^{-1}$ of oleic acid, $0.096 \mathrm{~mol} \mathrm{~L}^{-1}$ of $n$-butanol and $1 \mathrm{~g} \mathrm{~L}^{-1}$ of enzyme at $800 \mathrm{rpm}$ rotation speed.

\section{Table 2}

Effect of mobile phase flow rate on oleic acid conversion in the CPR. Operating conditions: $n$-BuOH/oleic acid $=3(\mathrm{~mol} / \mathrm{mol}), R$. miehe concentration $=0.5 \mathrm{~g} . \mathrm{L}^{-1}$, rotation speed $800 \mathrm{rpm}$. CPR is operated at controlled room temperature $\left(22^{\circ} \mathrm{C}\right)$. Experimental data of conversion obtained in the CPR correspond to experiments reported in our previous work [2].

\begin{tabular}{ll}
\hline Flow rate $\left(\mathrm{mL} \cdot \mathrm{min}^{-1}\right)$ & Oleic acid conversion \\
\hline 2.5 & $0.73 \pm 0.04$ \\
3 & $0.60 \pm 0.03$ \\
5 & $0.46 \pm 0.02$ \\
10 & $0.26 \pm 0.02$ \\
\hline
\end{tabular}

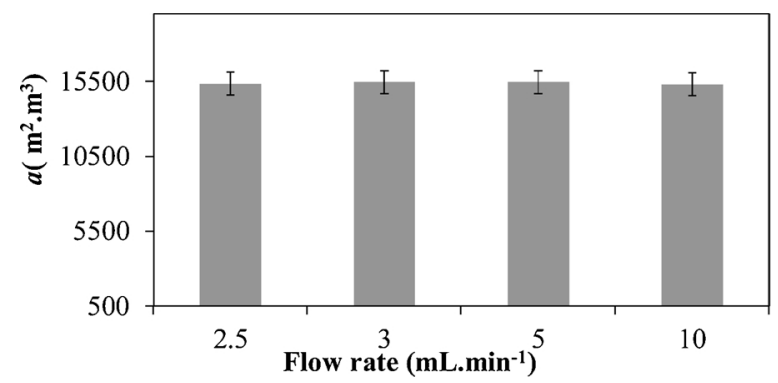

Fig. 5. Effect of mobile phase flow rate on the specific interfacial area of the CPR. Operating conditions: $n$-BuOH/oleic acid $=3(\mathrm{~mol} / \mathrm{mol}), R$. miehei concentration $=0.5 \mathrm{~g} \mathrm{~L}^{-1}$, rotation speed $800 \mathrm{rpm}$. CPR is operated at controlled room temperature $\left(22^{\circ} \mathrm{C}\right)$.

It is seen that conversion decreases when mobile flow-rate is increased because of the reduction of the residence time in the continuous reactor.

From experimental data of conversion in the CPR used as a continuous plug flow reactor, using Eq. (2), the knowledge of the parameters of the kinetic equation now enables us to determine the values of the specific interfacial area of the CPR (referred to the total volume of the reactor), $a_{C P R}$, because it is the only unknown variable. Results are reported on Fig. 5. It is observed that specific interfacial area is very similar for all values of the mobile phase flow-rate (around 15,360 $\mathrm{m}^{2}$ $\mathrm{m}^{-3}$ ). These results also indicate clearly that the specific interfacial area is not dependent from the mobile phase flow, which is a striking difference compared to "dynamic mixing intensified reactors" such as Corning or Chart reactors, as we mentioned in the introduction. Indeed, CPR compares rather with the NiTech Technology (tubular reactor including annular-baffles), where the pulsation is the main actor on diphasic hydrodynamics inside the reactor [24,25]. Detailed description of the NiTech reactor can be found in [7]. Note also that the value of the specific interfacial area is rather high and confirms the efficiency of this type of reactor when interfacial area is a key parameter [11].

As a comparison Adelmann et al. evaluated the interfacial area of a CPC device in various solvent systems [23]. They reported a value of the specific interfacial area, referred to the total CPR cell volume, between one and two thousands of $\mathrm{m}^{2} \cdot \mathrm{m}^{-3}$.

\section{Conclusion}

This study has established a simple modelling of the operation of an enzymatic esterification in a CPR (a CPC device used as a reactor) based on the equation of an ideal plug flow reactor, assuming two very probable hypotheses: i) negligible axial dispersion ii) negligible mass transfer resistance. Such a modelling requires the knowledge of the intrinsic enzymatic kinetics that can be obtained from initial velocity studies in the literature or, if not available, issued from preliminary experimental works in a conventional batch reactor. We performed here such preliminary experiments to identify the kinetic constants. To do so, the value of the partition coefficient of partitioning species, here only the butanol, must be known and was taken from our previous works [15].

The specific interfacial area in the CPR is a critical parameter that was estimated here from a set of experimental conversion values at different flow rates, using the modelling proposed in this work. The specific interfacial area was shown to be high (around 15,000 $\mathrm{m}^{2} . \mathrm{m}^{-3}$ ) and also to be almost independent of the flow rate. So, this value can be used for any other conditions of flow rate or initial concentrations, provided that retention and rotation speed are kept constant. This is an important result which characterizes this type of intensified reactor and highlights the difference with so called "dynamic intensified reactors". Also, knowledge of interfacial area generated in this device gives access to optimization and better understanding of its operation as a novel intensified two phase enzymatic reactor. Indeed, this study, originally aimed at a better knowledge of this new type of reactor, proved also to be useful, when intrinsic kinetics are available, as an indirect way to estimate the specific interfacial area in such centrifugal systems. Note that this estimation of the specific interfacial area value remains valid for a more conventional use of this apparatus as a chromatographic device. Such estimation of specific interfacial area was not yet available as only the volumetric mass transfer coefficient, $k_{L} a$, had been studied in the literature. In the volumetric mass transfer coefficient, the specific interfacial area, $a$, is not uncoupled from the mass transfer coefficient, $\mathrm{k}_{\mathrm{L}}[8,23]$ while only the value of the specific interfacial area is of importance for operation of interface catalyzed enzymatic reactions because it is directly related to the amount of effective biocatalyst in the system.

\section{Acknowledgements}

The authors wish to thank the French Agence Nationale de la Recherche (ANR 12-CDII-0009) for financial support.

\section{References}

[1] T. Van Gerven, A. Stankiewicz, Structure, energy, synergy, time-the fundamentals of process intensification, Ind. Eng. Chem. Res. 48 (5) (2009) 2465-2474, https:// doi.org/10.1021/ie801501y.

[2] C. Nioi, D. Riboul, P. Destrac, A. Marty, L. Marchal, J.S. Condoret, The centrifugal partition reactor, a novel intensified continuous reactor for liquid-liquid enzymatic reactions, Biochem. Eng. J. 10315 (2015) 227-233, https://doi.org/10.1016/j.bej. 2015.07.018.

[3] A.P. Foucault, A. Foucault (Ed.), Centrifugal Partition Chromatography, Marcel Dekker, Inc., New York, 1994.

[4] G.N. Kraai, J.G.M. Winkelman, J.G. de Vries, H.J. Heeres, Kinetic studies on the Rhizomucor miehei lipase catalyzed esterification reaction of oleic acid with 1butanol in a biphasic system, Biochem. Eng. J. 41 (1) (2008) 87-94, https://doi org/10.1016/j.bej.2008.03.011.

[5] G.N. Kraai, B. Schuur, F. van Zwol, H.H. van de Bovenkamp, H.J. Heeres, Novel highly integrated biodiesel production technology in a centrifugal contactor separator device, Chem. Eng. J. 154 (2009) 15384-15389, https://doi.org/10.1016/j. 
cej.2009.04.047.

[6] J. Krause, J. Merz, Comparison of enzymatic hydrolysis in a centrifugal partition chromatograph and stirred tank reactor, J. Chromatogr. A 1504 (2017) 64-70, https://doi.org/10.1016/j.chroma.2017.05.006.

[7] S. Elgue, A. Conté, A. Marty, J.S. Condoret, Continuous lipase esterification using process intensification technologies, J. Chem. Technol. Biotechnol. 132 (2013) 406-409, https://doi.org/10.1002/jctb.4247.

[8] L. Marchal, J. Legrand, A. Foucault, Mass transport and flow regimes in centrifugal partition chromatography, AIChE J. 48 (8) (2002) 1692-1704, https://doi.org/10. 1002/aic.690480811.

[9] S. Hari Krishna, N.G. Karanth, Lipases-catalyzed synthesis of isoamyl butyrate: a kinetic study, Biochim. Biophys. Acta 1547 (2001) 262-267, https://doi.org/10. 1016/S0167-4838(01)00194-7.

[10] J.J. Adrie Straathof, Enzymatic Catalysis Via Liquid-Liquid Interfaces, Wiley periodicals, Inc. Biotechnol. Bioeng. 83 (2003) (2003) 371-375, https://doi.org/10. 1002/bit.10688.

[11] S. Saktaweewong, P. Phinyocheep, C. Ulmer, E. Marie, A. Durand, P. Inprakhon, Lipase activity in biphasic media: why interfacial area is a significant parameter? J. Mol. Catal., B Enzym. 70 (2011) 8-16, https://doi.org/10.1016/j.molcatb.2011.01. 013.

[12] W. Chulaksananukul, J.S. Condoret, D. Combes, Kinetics of geranyl acetate synthesis by lipase-catalysed transesterification in n-hexane, Enzym. Microb. Technol. 14 (1992) 293-298, https://doi.org/10.1016/0141-0229(92)90154-G.

[13] S.H. Krishna, N.G. Karanth, Lipases and lipase-catalyzed esterification reactions in nonaqueous media, Catal. Rev. Sci. Eng. 44 (2002) 499-591, https://doi.org/10. 1081/CR-120015481.

[14] R.D. Schmid, R. Verger, Lipases: interfacial enzymes with attractive applications, Angew. Chem. Int. Ed. Engl. 37 (12) (1998) 1608-1633, https://doi.org/10.1002/ (SICI)1521-3773(19980703)37:12 < 1608:AID-ANIE1608 > 3.0.CO;2-V.

[15] J. Scillipoti, C. Nioi, A. Marty, S. Camy, J.S. Condoret, Prediction of conversion at equilibrium for lipase esterification in two-phase systems, Biochem. Eng. J. 117
(2017) 162-171, https://doi.org/10.1016/j.bej.2016.10.012.

[16] Y. Cajal, A. Svendsen, J. De Bolos, S.A. Patkar, M.A. Alsina, Effect of the lipid interface on the catalytic activity and spectroscopic properties of a fungal lipase, Biochimie 82 (2000) 1053-1061, https://doi.org/10.1016/s0300-9084(00) 01189-5.

[17] G.E. Briggs, J.B.S. Haldane, A note on the kinetics of enzyme action, Biochem. J. 19 (2) (1925) 338-339 PMID:16743508 PMCID:PMC1259181.

[18] E. Noor, A. Flamholz, W. Liebermeister, A. Bar-Even, R. Milo, A note on the kinetics of enzyme action: a decomposition that highlights thermodynamic effects, FEBS Lett. 587 (17) (2013) 2772-2777, https://doi.org/10.1016/j.febslet.2013.07.028.

[19] A.I. Vorobeva, M. Karapetyants, Jean Vidal, Thermodynamics, Chapter 9, Kh., Zh. Fiz. Khim. 41, 1144 Liquid-liquid and liquid-vapor equilibria, 1967, pp. 330-335.

[20] A.C. Oliveira, M.F. Rosa, M.R. Aires-Barros, J.M.S. Cabral, Enzymatic esterification of ethanol and oleic acid-a kinetic study, J. Mol. Catal. B: Enzymatic 11 (2001) 999-1005, https://doi.org/10.1016/s1381-1177(00)00039-4.

[21] G. Sandoval, J.S. Condoret, P. Monsan, A. Marty, Esterification by immobilized lipase in solvent-free media: kinetic and thermodynamic arguments, Biotechnol. Bioeng. 78 (2002) 313-320, https://doi.org/10.1002/bit.10224.

[22] C. Albasi, N. Bertrand, J.P. Riba, Enzymatic hydrolysis of sunflower oil in a standardized agitated tank reactor, Bioprocess. Bioeng. 20 (1999) 77-81, https://doi. org/10.1002/(sici)1097-4660(199707)69:3 < 329:aid-jctb712>3.0.co;2-x.

[23] S. Adelmann, C. Schwienheer, G. Schembecker, Multiphase flow modeling in centrifugal partition chromatography, J. Chromatogr. A 1218 (36) (2011) 6092-6101, https://doi.org/10.1016/j.chroma.2011.01.063.

[24] A. Mazubert, M. Poux, J. Aubin, Intensified processes for FAME production from waste cooking oil: a technological review, Chem. Eng. J. 233 (2013) 201-223, https://doi.org/10.1016/j.cej.2013.07.063.

[25] J. Sun, J. Ju, L. Ji, L. Zhang, N. Xu, Synthesis of biodiesel in capillary microreactors, Ind. Eng. Chem. Res. 47 (2008) 1398-1403, https://doi.org/10.1016/j.proche. 2014.05.020. 